\title{
Antioxidant Property, Cytotoxicity and Antimicrobial Activity of Lasia spinosa Leaves
}

\author{
Durajan Goshwami, ${ }^{1}$ Md. Mostafizur Rahman, ${ }^{2}$ Md. Abdul Muhit, ${ }^{2}$ \\ Md. Saiful Islam ${ }^{2}$ and Mukhtar Ansari ${ }^{1}$ \\ ${ }^{1}$ Department of Pharmacology, National Medical College Teaching Hospital and Research Center \\ Birgunj, Parsa \\ ${ }^{2}$ Department of Clinical Pharmacy \& Pharmacology, Faculty of Pharmacy, \\ University of Dhaka, Dhaka-1000, Bangladesh \\ e-mail:durajan22@gmail.com
}

\begin{abstract}
This study was undertaken to evaluate antioxidant property, cytotoxicity and antimicrobial activity of Lasia spinosa leaves. Ethyl acetate soluble partitionate of the methanolic extract of the plant material showed significant antioxidant property using DPPH (1,1-diphenyl-2-pecrylhydrazyl) assay with $\mathrm{IC}_{50}$ value of $16.42 \mu \mathrm{g} / \mathrm{ml}$. In the brine shrimp lethality bioassay, $\mathrm{LC}_{50}$ values obtained from the best fit line slope were $0.544,3.181$, and $4.096 \mu \mathrm{g} / \mathrm{mL}$ for standard (vincristine sulphate), dichloromethane and ethylacetate soluble partitionates of the methanolic extract respectively. The leaves extracts showed mild antimicrobial property.
\end{abstract}

Key words: antimicrobial, antioxidant, cytotoxic, Lasia spinosa

\section{Introduction}

Lasia spinosa (Bengali name: Kantakachu, Family: Araceae) is a stout, intensely prickly marsh plant with creeping rootstock, found in low-lying shady areas, near water bodies. It is a spinous perennial herb that is mostly distributed in Southeast Asia. The plant usually grows surrounding ponds, and its shoots are consumed as traditional food in many communities of Southeast Asia. It is an ethnobotanically important medicinal plant. Different parts of the plant are used for various ailments, e.g., colic, rheumatism and intestinal diseases. In Khagrachari, an area of Bangladesh, the corm is used as a remedy for throat affections, whereas leaves and corms together are used for cure of piles (Yusuf et al. 2009). The stem is used as antitussive, expectorant, is boiled and used in bathes far relieving itching from roseolar infantum, measles, rubella and other skin disorders. The tubers are used for the treatment of rheumatoid arthritis, constipation and to purify blood in Rajshahi and Natore district of Bangladesh (Rahmatullah et al. 2010). In Naga tribes of India, the leaves are used for intestinal disorders, and its anticestodal effect was determined by Yadav and Temjenmongla(Yadav \& Temjenmongla 2006). The rhizomes of the plant possess antioxidant, antimicrobial and cytotoxic activities (Hasan et al. 2011, Shefana \& Ekanayake 2009). Deb et al. demonstrated antinociceptive, antinflammatory and antidiarrhoeal activities of the root extract(Deb et al. 2010).

\section{Methodology}

\section{Collection of the plant}

Lasia spinosa leaves were collected from Sundarban, Khulna, Bangladesh during May 2011. The plant was identified from the Department of Botany, Dhaka University, Dhaka and a specimen has been deposited in the Dhaka University Herbarium, Dhaka (Accession No. DUSH 1940).

\section{Extraction and isolation}

The leaves of the plant were collected in fresh condition. The dried and coarse powder (650 g) was extracted with methanol (2.5 l) in an air tight flatbottomed container for 15 days at room temperature 
with occasional stirring. The extract was then filtered through a cotton plug followed by a Whatman No. 1 filter paper. The filtrate was concentrated using a rotary evaporator at low temperature and pressure to afford crude methanolic extract ( $23 \mathrm{~g}$ ). The crude extract (5 g) was dissolved in $10 \%$ aqueous methanol which was subsequently extracted first with petroleum ether (PE), then dichloromethane (DCM) and finally with ethyl acetate (EA). The aqueous methanolic extract was preserved as aqueous fraction (AQ) (Kupchan \& Tsou 1973,Van Wagenen et al. 1993). All the fractions were evaporated to dryness by using a rotary evaporator and kept in airtight containers for further analysis.

\section{Test organisms}

Five Gram positive, 8 Gram negative bacteria and 3 fungal species were collected as pure cultures from the Institution of Nutrition and Food Science (INFS), University of Dhaka. The microorganisms were maintained on nutrient agar medium (Merck, Germany). Artemia salina (brine shrimp) eggs were collected from an aquarium shop (imported from Thailand) and hatched to get mature nauplii for brine shrimp lethality bioassay.

\section{Screening of antioxidant activity}

The free radical scavenging activity of the extracts on the stable radical 1,1-diphenyl-2-pecrylhydrazyl (DPPH) was determined following standard procedure (Feresin et al. 2002). Two miligrams of each of the partitionated test sample was dissolved in methanol and solution of varying concentrations such as 500 , 250, 125, 62.50, 31.25, 15.62, 7.81, 3.90, 1.95 and 0.97 $\mu \mathrm{g} / \mathrm{ml}$ were prepared by serial dilution technique. Then $2 \mathrm{~mL}$ of each of the test sample was mixed with $3 \mathrm{ml}$ of a DPPH-methanol solution $(20 \mu \mathrm{g} / \mathrm{ml})$ and the mixture was allowed to stand for 20 minutes for reaction completion. The absorbance was determined at a wave length of $517 \mathrm{~nm}$ and the corresponding percentage of inhibition was calculated by using the following equation:

$$
\% \text { Inhibition }=\frac{1-\left(\text { Absorbance }_{\text {sample }}\right.}{\text { Absorbance } \left._{\text {control }}\right)} \times 100
$$

Then \% inhibitions were plotted against respective concentrations used and $\mathrm{IC}_{50}$ was calculated from the graph using butylated hydroxy toluene (BHT), a potential antioxidant, as positive control. The experiment was repeated thrice and the mean $\mathrm{IC}_{50}$ value was taken to compare with BHT.

\section{Screening of cytotoxic activity}

In brine shrimp lethality bioassay, dimethyl sulfoxide (DMSO) solutions of the four partitionates (PE, DCM, EA and AQ) were applied to A. salina for 24 hours (Mclaughlin \& Rogers 1998, Meyer et al. 1982). For the experiment, $4 \mathrm{mg}$ of each of the extracts were dissolved in DMSO and solutions of varying concentrations $(400,200,100,50,25,12.50,6.25,3.125$, $1.562,0.781 \mu \mathrm{g} / \mathrm{ml}$ ) were obtained by serial dilution technique. The solutions were then added to the premarked vials containing ten live brine shrimp nauplii in $5 \mathrm{ml}$ simulated sea water. After 24 hours, the vials were inspected using a magnifying glass and the number of survived nauplii in each vial was counted. From this data, the \% lethality of brine shrimp nauplii was calculated for each concentration. The median lethal concentration $\left(\mathrm{LC}_{50}\right)$ of the test samples was obtained by plotting percentage of the shrimp killed against the logarithm of the sample concentration.

\section{Screening of antimicrobial activity}

The antibacterial activity was carried out by the disc diffusion method using nutrient agar medium (Bauer et al. 1966). The sterile Matricel (BBL, cocksville USA) $6.0 \mathrm{~mm}$ filter paper discs, impregnated with $400 \mu \mathrm{g}$ of petroleum ether, dichloromethane, ethyl acetate and aqueous extract, were placed gently on the previously marked zones in the agar plates. Standard Ciprofloxacin discs (50 $\mu \mathrm{g} /$ disc) were used as positive control to ensure the activity against test organisms. The zones of inhibition produced by the extracts were measured thrice and its mean value was taken to compare with the standard.

\section{Statistical analyses}

Regression analysis was carried out for analyzing the data obtained from brine shrimp lethality bioassay to study the relationship between different samples and vincristine sulphate.

\section{Results and Discussion}

The study was performed to determine the antioxidant, cytotoxic and antimicrobial activity of $L$. spinosa leaves. The antioxidant property of the plant was evaluated using 1, 1-diphenyl-2-pecrylhydrazyl (DPPH) free radical scavenging test following previously described procedure (Pietta et al. 1998, Velioglu et al. 1998). The cytotoxic activity of plant materials was performed by using brine shrimp lethality bioassay (Meyer et al. 1982). The 
antimicrobial activity was performed against different gram-positive, gram-negative bacteria and fungi using disc diffusion technique (Wilkinson 2007).

The partitioning of crude methanolic extract yielded $750 \mathrm{mg}, 590 \mathrm{mg}$ and $305 \mathrm{mg}$ partitionate of PE, DCM and EA respectively.

The antioxidant activities of various extracts of leaves of $L$. spinosa are shown in Table 1 . The ethyl acetate fraction (EA) showed the highest free radical scavenging activity with $\mathrm{IC}_{50}$ value $16.42 \mu \mathrm{g} / \mathrm{ml}$ in comparison to positive control (BHT). At the same time the aqueous fraction (AQ) also exhibited moderate antioxidant potential having $\mathrm{IC}_{50}$ value of $73.20 \mu \mathrm{g} / \mathrm{ml}$. Table 2 shows the result of the brine shrimp lethality testing of various extractives of $L$. spinosa after 24 hours of exposure to the samples and the positive control, vincristine sulphate (VS). The $\mathrm{LC}_{50}$ values were found to be $16.69,3.18,4.09,98.66$ and $0.544 \mu \mathrm{g} /$
mL for petroleum ether, dichloromethane, ethyl acetate, aqueous and vincristine sulphate respectively. In comparison to positive control (Vincristine sulphate), the cytotoxicity exhibited by dichloro methane (DCM) soluble partitionate of methanolic extract was promising. On the other hand, ethyl acetate (EA) partitionate demonstrated comparable cytotoxicity in comparison with dichloro methane (DCM).

Table 1. The result of antioxidant activity of petroleum ether (PE), dichloromethane (DCM), ethyl acetate (EA) and aqueous (AQ) soluble partitionate of methanolic extract and positive control butylated hydroxy toluene (BHT)

\begin{tabular}{c|c}
\hline Sample & IC $_{\mathbf{5 0}}(\boldsymbol{\mu g} / \mathbf{m L})$ \\
\hline BHT & 23.19 \\
PE & 174.78 \\
DCM & 248.82 \\
EA & 16.42 \\
AQ & 73.20 \\
\hline
\end{tabular}

Table 2. The result of cytotoxicity of petroleum ether (PE), dichloromethane (DCM), ethyl acetate (EA) and aqueous (AQ) soluble partitionate of methanolic extract and positive control vincristine sulphate (VS) on brine shrimp nauplii

\begin{tabular}{cccc}
\hline Sample & $\mathbf{L C}_{\mathbf{5 0}}(\boldsymbol{\mu g} / \mathbf{m L})$ & Regression equation & $\mathbf{R}^{2}$ \\
\hline VS & 0.544 & $\mathrm{y}=33.22 \mathrm{x}+58.78$ & 0.958 \\
PE & 16.696 & $\mathrm{y}=40.06 \mathrm{x}+1.022$ & 0.931 \\
DCM & 3.181 & $\mathrm{y}=32.21 \mathrm{x}+33.81$ & 0.858 \\
EA & 4.096 & $\mathrm{y}=34.62 \mathrm{x}+28.80$ & 0.848 \\
AQ & 98.663 & $\mathrm{y}=30.80 \mathrm{x}-11.42$ & 0.708 \\
\hline
\end{tabular}

Table 3. Antimicrobial activity of petroleum ether (PE), dichloromethane (DCM), ethyl acetate (EA) and aqueous (AQ) fraction of $L$. spinosa leaves and positive control Ciprofloxacin (CF)

\begin{tabular}{|c|c|c|c|c|c|}
\hline \multirow[t]{2}{*}{ Test bacteria and fungi } & \multicolumn{4}{|c|}{ Diameter of zone of inhibition (mm) } & \multirow[b]{2}{*}{$\mathbf{C F}$} \\
\hline & $\mathbf{P E}$ & DCM & EA & $\mathbf{A Q}$ & \\
\hline \multicolumn{6}{|l|}{ Gram positive } \\
\hline Bacillus cereus & 8 & 7 & 8 & - & 45 \\
\hline Bacillus megaterium & - & - & - & - & 48 \\
\hline Bacillus subtilis & 9 & 9 & 9 & 9 & 43 \\
\hline Staphylococcus aureus & 7 & 7 & 8 & - & 46 \\
\hline Sarcina lutea & 7 & 7 & 7 & - & 45 \\
\hline \multicolumn{6}{|l|}{ Gram negative } \\
\hline Escherichia coli & 7 & - & 8 & - & 45 \\
\hline Pseudomonas aeruginosa & 7 & 7 & - & - & 46 \\
\hline Salmonella paratyphi & 8 & 8 & 9 & - & 45 \\
\hline Salmonella typhi & 7 & 7 & - & - & 46 \\
\hline Shigella boydii & 7 & 7 & - & - & 45 \\
\hline Shigella dysenteriae & 10 & & - & - & 45 \\
\hline Vibrio mimicus & 7 & 7 & - & - & 46 \\
\hline Vibrio parahemolyticus & - & - & - & - & 45 \\
\hline \multicolumn{6}{|l|}{ Fungi } \\
\hline Candida albicans & 10 & 10 & 10 & - & 45 \\
\hline Aspergillus niger & 10 & 10 & 8 & - & 45 \\
\hline Sacharomyces cerevacae & 7 & 7 & - & - & 44 \\
\hline
\end{tabular}


The antimicrobial effects of $L$. spinosa leaves against various test organisms are shown in Table 3 . The aqueous extract exhibited no activity against the tested microorganisms at a concentration of $400 \mu \mathrm{g} /$ disc. The petroleum ether extract showed mild inhibitory activity against various Gram-negative bacteria such as Shigella dysenteriae $(10 \mathrm{~mm})$. It showed mild antifungal activity against Candida albicans $(10 \mathrm{~mm})$ and Aspergillus niger (10 mm). The dichloromethane extract revealed mild antifungal activity against Candida albicans (10 mm) and Aspergillus niger (10 $\mathrm{mm}$ ) and the ethyl acetate extract showed mild antifungal activity against Candida albicans (10 mm).

The extracts of leaves of $L$. spinosa showed significant antioxidant and cytotoxic properties with non significant antimicrobial properties. Further investigation is required for isolating the specific bioactive constituents responsible for antioxidant and cytotoxic activities.

\section{Acknowledgements}

The authors would like to acknowledge the Head of the Department of Clinical Pharmacy and Pharmacology, Faculty of Pharmacy, University of Dhaka, Dhaka, Bangladesh for providing facility and moral support to carry out this research.

\section{References}

Bauer, A.W., W.M. Kirby, J.C. Sherris and M.M. Turck, 1966. Antibiotic susceptibility testing by a standardized single disc method. Am. J. Clin. Pathol. 45(4):493-496.

Deb, D., S. Dev, A.K. Das, D. Khanam, H. Banu, M.M. Shahriar et al. 2010. Antinociceptive, anti-inflammatory and antidiarrhoeal activities of the hydroalcoholic extract of Lasia spinosa Linn. (Araceae) roots. Lat. Am. J. Pharm. 29(8):1269-1276.

Feresin, G. E., A. Tapia, R. A. Gutierrez, C. Delporte, E.N. Backhouse and G. Schmeda-Hirschmann. 2002. Free radical scavengers, anti-inflammatory and analgesic activity of acaena magellanica. J. Pharm. Pharmacol., 54(6):835-844.
Hasan, C.M., F. Alam, M. Haque, M.H. Sohrab, M.A. Monsur and N. Ahmed. 2011. Antimicrobial and Cytotoxic Activity from Lasia spinosa and Isolated Lignan Lat. Am. J. Pharm., 30(3): 550-553.

Kupchan, S.M. and G. Tsou. 1973. Tumor inhibitors. LXXXI, structure and partial synthesis of fabacein. J. Org. Chem. 38: 178.

Mclaughlin, J.L. and L.L. Rogers. 1998. The use of biological assays to evaluate botanicals. Drugs Infor. Journal, 32:513-524.

Meyer, B.N., N.R. Ferrigni, J.E. Putnam, J.B. Jacobsen, D.E. Nicholsand and J.L. Mclaughlin. 1982. Brine shrimp; a convenient general bioassay for active plant constituents. Plant medica 45:31-34.

Pietta, P., P. Sionetti and P. Mauri. 1998. Antioxidant activity of selected medicinal plants. Journal of Agriculture and Food Chemistry 46:4487-4490.

Rahmatullah, M., R. Jahan, A.K. Azad, S. Syeda, M.M. Rahman, A.R. Chowdhury et al. 2010. Medicinal plants used by folk medicinal practitioners in three villages of Natore and Rajshahi districts, Bangladesh. Am. Eurasian J. Sustain. Agric. 4(2): 211-218.

Shefana, A.G. and S. Ekanayake. 2009. Some nutritional aspects of Lasia spinosa (Kohila). Vidyodaya J. of Sci. 14:59-64.

Van Wagenen, B.C., R. Larsen, J.H. Cardellina, D. Ran Dazzo, Z.C. Lidert and C.Swithenbank. 1993. Ulosantoin, a potent insecticide from the sponge Ulosa ruetzleri. J. Org. Chem. 58:335-337.

Velioglu, Y.S., G. Mazza, Y.L. Gao and B.D. Oomah. 1998. Antioxidant activity and total phenolics in selected fruits, vegetables and grain products. Journal of Agriculture and Food Chemistry 46:4113-4117.

Wilkinson, J.M. 2007. Methods for testing the antimicrobial activity of extracts. In: Modern phytomedicine turning medicinal plants into drugs (Eds. I. Ahmad, F. Aqil, M. Owais, ). Wiley-VCH, Germany, Pp.157-169.

Yadav, A. K. and Temjenmongla. 2006. Anticestodal efficacy of Lasia spinosa extract against experimental Hymenolepis diminuta infections in rats. Pharm. Biology. 44(7): 499-502.

Yusuf, M., J. U. Chowdhury, M.A. Wahab and J. Begum, 2009. Medicinal plants of Bangladesh, Bangladesh Council of Scientific and Industrial Research, Dhaka. 391p. 